\title{
Interactive comment on "Impact of urban canopy meteorological forcing on aerosol concentrations" by Peter Huszar et al.
}

\section{Anonymous Referee \#3}

Received and published: 11 September 2018

General Comments: The manuscript by Huszar et al. is an interesting paper in which the authors combine the regional climate model RegCM4, land-surface model CLM4.5 and the chemistry transport model CAMx to investigate the impact of urban meteorological forcing on the surface fine aerosol (PM2.5) concentrations and its components during the summer seasons from 2001-2005 in Europe. The manuscript is well-written and the results and conclusions are properly presented. Considering its scientific significance, I recommend this manuscript to be accepted and published in ACP only after authors address the following comments.

Specific Comments: In P10, L15 authors mentioned that "largest contribution is made by sulfates and nitrates being around $50 \%$, while sulfates dominate especially over eastern European cities". What is the reason for the sulfate dominance over eastern 


\section{Europe?}

It is not clear to me how the input data for building heights and street width is used in CLM4.5 on a $10 \mathrm{~km} \times 10 \mathrm{~km}$ scale. What are the sources of this data?

In P11, L19 authors commented "The SOA is an exception here, where concentrations are suppressed all over the domain peaking over urban areas up to $-0.04 \mu \mathrm{gm}-3$ ". What is the reason for this exception?

Technical Comments: Please correct all the typing errors throughout the manuscript. I have listed some of them below: P1, L4: "increase" instead of "increases"

P1, L8-9: "Then" instead of "Than"

P1, L11: "decrease" instead of "decreases"

P5, L32-33: References in parentheses?

P6, L7: "CH4"

P7, L26: "Therefore" instead of "Therefor"

P8, L6: "7-8 pm" instead of "19-20 pm"

P9, L5: "northern" instead of "norther"; "southern" instead of "souther"

P9, L7: "are" instead of "ale"

P10, L23: "therefore" instead of "there for"

Interactive comment on Atmos. Chem. Phys. Discuss., https://doi.org/10.5194/acp-2018-415, 2018. 